\title{
有机化学协同课程群的矩阵型育人模式探索
}

\author{
王朝霞，罗千福，徐首红* \\ 华东理工大学化学与分子工程学院, 上海 200237
}

摘要: 作为 “金课” 建设的重要内容, 课程思政已成为课程改革与建设的热点。本文以有机化学课程为核心, 以高等有 机化学与糖化学基础课程为外延, 构建协同课程群。通过知识梳理, 重整教学内容, 使之在不同课程间合理对接, 循序 渐进, 推动专业教学向能力与素质导向型转变。同时, 立足有机化学学科, 建设思政与人文资源库。依据课程特色, 在 协同课程群中构建矩阵育人模式，将思政教育自然和谐地融入到化学教育中，真正做到润物无声，立德树人。

关键词: 课程思政; 有机化学; 课程群; 协同; 育人模式

中图分类号: G64; O6

\section{Exploring the Matrix-Style Education Model in the Collaborative Courses of Organic Chemistry}

\author{
Zhaoxia Wang, Qianfu Luo, Shouhong Xu * \\ School of Chemistry and Molecular Engineering, East China University of Science \& Technology, Shanghai 200237, China.
}

\begin{abstract}
As an important content of constructing "golden courses", ideological and political education in various courses has become a focus of curriculum reform and construction. This article takes organic chemistry as the core course and advanced organic chemistry and fundamentals of carbohydrate chemistry courses as an extension to build a collaborative curriculum group. Through combing knowledge, we build a reasonable connection between courses by reorganizing the teaching contents, so as to gradually promote transformation from the professional teaching to the ability and quality-oriented teaching. At the same time, based on the discipline of organic chemistry, we build an ideological and humanistic resource base. According to the characteristics of the courses, we are committed to building a matrix-style education model in the collaborative course group, integrating ideological and political education into chemistry education naturally and harmoniously, and truly moisturizing things silently and establishing morality.
\end{abstract}

Key Words: Course ideology and politics; Organic chemistry; Curriculum group; Collaboration; Education mode

课程思政建设是当前专业课程教学改革的重要内容, 其核心是在专业课的教学中实现知识传授、 能力培养和价值引领的有机融合，将教学回归到 “教书育人” 的初心和本源 ${ }^{[1]}$ 。

2020年, 华东理工大学化学与分子工程学院获批上海市高校课程思政领航计划重点改革领航学 院, 在 15 门建设课程中, 有机化学教研组承担的有机化学、高等有机化学、糖化学基础等课程位列 其中。尽管课程名称不同, 但都立足于有机化学学科, 因此, 教研组尝试以这三门课程为协同课程

收稿: 2020-08-03; 录用: 2020-09-23; 网络发表: 2020-10-09

”通讯作者, Email: xushouhong@ecust.edu.cn

基金资助: 教指委教学研究与实践项目(化学类专业基础课程思政建设与实践, H20200507); 华东理工大学 2019 年课程思政教学改革示范课程 建设; 华东理工大学 2019 年专创融合示范课程建设 
群构建矩阵型育人模式, 探索专业课程的思政教学改革实践。

\section{1 梳理并重整教学内容, 搭建协同课程群的矩阵育人模式}

我们知道, 所谓矩阵模式, 实际是借用了数学的概念, 横向构建协同课程群, 纵向进行思政育 人设计, 使课程思政在协同课程间形成一个知识传授、能力培养和价值引领自然融合、协同推进的 多维体系，有效提高育人效果。

在本课程群中, 有机化学是理论基础, 高等有机化学和糖化学基础课程是对前者的深化与拓展。 因此, 总体思路首先是以有机化学课程为核心、以高等有机化学和糖化学基础课程为外延构建一个 协同课程群, 继而抓住三门课程的共性, 同时又兼顾各自特性, 梳理并重整教学内容, 统筹安排, 将思 政元素与专业知识合理对接, 构建矩阵型育人模式, 有的放矢地进行课程群的思政建设, 使这三门 专业课同向同行, 推动专业教学由知识导向型向能力与素质导向型转变的同时, 完成立德树人的根 本任务。

\section{1 重整教学内容, 在教学设计中切实推进能力与素质的提升}

对化学专业大类的学生而言, 有机化学是贯穿大二全学年的基础必修课; 高等有机化学和糖化 学基础分别是开设在大三的专业必修和专业选修课程。高等有机化学偏重于知识的深化, 糖化学基 础偏重于知识的拓展, 是有机化学的后续课程。对三者组成的协同课程群, 首先要进行知识梳理, 理 顺并重整相关教学内容 ${ }^{[2]}$ 。对各课程间相互关联的知识点, 一定要避免教学内容的简单重复, 纵向 注重知识深度的递进、横向注重学科间知识的交叉与拓展。落实到实践上即是明确各课程教学的知 识深度与侧重点, 合理对接, 有效实现相同知识、理论在不同课程间的传承与深化, 惟其如此, 才 能在教学实践中循序渐进地夯实学生的理论基础, 并通过引导切实推进其专业能力与素质的提升 ${ }^{[3]}$ 。

典型案例 $1:$ 碳正离子知识点的矩阵育人模式设计

碳正离子是有机反应中最重要的活泼中间体之一, 一直是大学有机化学和高等有机化学课程教 学中的一个重点和难点。其稳定性的大小直接影响着反应速率的快慢、反应方向、反应历程及产物 的结构等等 ${ }^{[4]}$, 以此为例, 教学设计如表 1 所示。

表 1 碳正离子知识点的矩阵育人模式设计

\begin{tabular}{|c|c|c|c|}
\hline 课程名称教案设计 & 有机化学 & 高等有机化学 & 糖化学基础 \\
\hline 参考教材 & $\begin{array}{l}\text { 《有机化学》(华东理工大学有机化学教 } \\
\text { 研组编)、《有机化学》(钱旭红主编)、 } \\
\text { 《基础有机化学》(荣国斌主编) }\end{array}$ & 《高等有机化学基础》(荣国斌编) & $\begin{array}{l}\text { 《糖化学基础》(陈国荣编)、《糖 } \\
\text { 化学》(孔繁祚编) }\end{array}$ \\
\hline 总学时 & 96 & 48 & 32 \\
\hline 本知识点学时分配 & $2-3$ & 2 & $1-2$ \\
\hline 教材编排 & 烯烃、卤代烃、醇等相应章节 & 活泼中间体一章单独列出 & 不单独列出 \\
\hline 教学内容 & 1. 经典碳正离子的结构与杂化状态 & 1. 综述有机化学课程中的碳正离子知识 & 以各种糖基化反应为重点进行 \\
\hline & 2. 各种电子效应对稳定性的影响 & 2. 经典碳正离子稳定性的综合分析 & 探讨 \\
\hline & $\begin{array}{l}\text { 3. 熟悉并理解伯、仲、叔等常见碳正离 } \\
\text { 子稳定性顺序 }\end{array}$ & 3. 非经典碳正离子的概念及应用 & \\
\hline 教学侧重 & 杂化轨道、电子效应等基础知识及典型 & 综合分析较复杂的经典与非经典碳正离子 & 理论联系实际, 探讨碳正离子对 \\
\hline & 应用 & 的稳定性及在有机反应中的应用 & 糖化学反应的影响 \\
\hline
\end{tabular}


(续表1)

\begin{tabular}{|c|c|c|c|}
\hline 课程名称教案设计 & 有机化学 & 高等有机化学 & 糖化学基础 \\
\hline 教学议题 & $\begin{array}{l}\text { 为什么一些 } \mathrm{S}_{\mathrm{N}} 1 \text { 反应产生了消旋或重排 } \\
\text { 产物? 请结合具体实例加以解释 }\end{array}$ & $\begin{array}{l}\text { 不同教材对苄基、烯丙基和叔丁基碳正离 } \\
\text { 子的稳定性有不同的排序, 提出你的看法 } \\
\text { 并给出相应的分析 }\end{array}$ & $\begin{array}{l}\text { 糖基化反应中，如何构建 } 1,2-\text { 反 } \\
\text { 式 } \beta \text { 型糖苷键? }\end{array}$ \\
\hline 教学方法 & $\begin{array}{l}\text {-课堂讲授 -讨论 } \\
\text {-案例教学 } \text {-课外作业 }\end{array}$ & $\begin{array}{l}\text {-课堂讲授 } \text {-讨论 } \\
\text {-课外作业 } \text {-课程小论文 }\end{array}$ & $\begin{array}{l}\text {-课堂讲授 } \text {-讨论 } \\
\text {-案例教学 } \text {-课外作业 }\end{array}$ \\
\hline 能力培养 & $\begin{array}{l}\text { 面对浩如烟海的有机反应, 学会透过现 } \\
\text { 象看本质, 抓住本质并举一反三解决相 } \\
\text { 关问题 }\end{array}$ & $\begin{array}{l}\text { 通过文献查阅与定性、定量分析, 对比各 } \\
\text { 种版本教材, 获得相对正确的结论。逐步 } \\
\text { 培养独立分析、解决有机化学相关较复杂 } \\
\text { 问题的学科素养与研究能力 }\end{array}$ & $\begin{array}{l}\text { 查阅文献, 从科研结果出发, 多 } \\
\text { 角度分析分子结构对碳正离子 } \\
\text { 及反应的影响, 锻炼科研思维能 } \\
\text { 力与学科素养 }\end{array}$ \\
\hline 价值引领 & $\begin{array}{l}\text { 物质的结构决定性质, 用马克思主义哲 } \\
\text { 学原理, 即内因与外因辨证关系原理解 } \\
\text { 决有机化学问题 }\end{array}$ & $\begin{array}{l}\text { 不盲从教材、文献或权威, 培养学生大胆 } \\
\text { 质疑并小心求证的科学精神 }\end{array}$ & $\begin{array}{l}\text { 学以致用、知行合一的科研能 } \\
\text { 力, 并自然过渡到责任担当与家 } \\
\text { 国情怀 }\end{array}$ \\
\hline
\end{tabular}

从表1可以看出: 虽然都针对碳正离子, 但在协同课程群里, 一定要避免知识的简单重复, 统筹 规划, 从教材编排、教学内容、教学侧重等方面重新进行教学设计, 并依据学情, 设计不同的教学 议题, 采取不同的教学方法, 循序渐进, 融入能力与素质培养目标, 同时, 尽可能把辩证与历史唯 物主义渗透到课程教学中去, 并从科学精神、家国情怀等角度进行价值引领。

典型案例2: 氢键理论

通过有机化学的初步学习, 学生已掌握氢键的基本概念并能进行简单的应用, 到高等有机化学 “有机分子的内外性质”一章, 教师要在帮助学生巩固原有知识的基础上, 结合实例, 引导学生分 析氢键对特定结构化合物的熔点、沸点、溶解度、酸碱性等的影响, 同时, 鼓励学生查阅基于氢键 作用的超分子化学的最新科研成果, 拓展学术视野、提高学科素养。尽管1936年科学界就提出了氢 键的概念, 但人们从未真正看见过氢键, 只能借助X射线衍射、拉曼光谱、中子衍射等技术进行间接 分析。2013年, 我国科学家䒾晓辉教授团队在超高真空和低温条件下, 利用自有技术改装原子力显 微镜, 实现了对分子间局域作用的直接成像, 首次直接观察到了 8-差基喹啉分子间氢键的高分辨图 像, 被《自然》杂志评述为 2013 年度最震撼的 3 幅图片之一, 为化学界争论多年的 “氢键的本质” 问 题提供直观证据。通过我国科学家的这一科研成果案例, 可以培养学生家国情怀, 增强其文化自信 ${ }^{[5]}$ 。 在糖化学基础课程中, 由于糖类化合物含有大量的羟基、羰基、(半)缩醛(酮)基团, 比如环糊精, 其 溶解度、超分子性质等都与氢键密切相关, 国内外研究也非常活跃, 典型实例层出不穷, 因此, 更 易联系实际，学以致用。

案例 3: 葡萄糖的结构

无论含有羟基的醇和酚, 还是含有炭基的醛和酮, 都是有机化学课程中 “含氧化合物”一章的 教学重点, 但同时含有羟基和羰基的 “糖类化合物” 一章却是简要介绍部分。在糖化学基础课程的 教学中, 教师就要抓住课程特点, 以葡萄糖为例, 从羟基和醛羰基的连接次序、位置、方式和空间 关系等处着眼, 引导学生反思。将基础有机及高等有机化学中的基本理论、立体化学、醇、醛等多 章知识融会贯通、综合运用: 首先从构造、构型、构象上认识葡萄糖结构, 继而深入认识对其物理 与化学性质的影响, 逐步培养本科生的科学思维能力 ${ }^{[6]}$ 。 


\section{2 统筹安排, 靶向性优化课程思政内容, 立德树人}

三门课程均立足有机化学学科, 因此, 教师在备课过程中要注意广泛收集素材, 建设有机化学协 同课程群的思政与人文资源库 ${ }^{[7]}$ 。对标《普通高等学校本科专业类教学质量国家标准》和《普通高等学 校专业认证标准》, 课程思政主要包含政治方向、思想品格、科学文化修养、家国情怀、传承文化、世 界观与方法论、国际视野等 7 个方面的内容 ${ }^{[1]}$ 。在教学过程中, 一方面把专业知识与具体案例合理对接, 实现思政教育与专业知识的自然融合 ${ }^{[8]}$; 另一方面, 构建矩阵型育人模式时, 要因课制宜, 突出课程自 身特色的同时，避免德育内容的简单重复，让思政教育多角度、全方位融入教学实践中。

典型案例 1 : 有机化学绪论课的德育教育

三门课中, 有机化学是最先启动的课程, 绪论课不仅是有机化学、还是协同课程群思政教育的 第一环, 教师必须重点把握。从有机化合物名称的由来, 到与有机化学密切相关的食品安全、环境 污染、化工安全生产等社会关注问题, 再到近期提倡的垃圾分类和新冠药物研发等社会热点问题, 无不蕴含着大量的德育元素 ${ }^{[9]}$, 教师在教学过程中要有所取舍, 注意点面结合。可以通过举例阐明 化学技术对于人类健康和社会环境的重大意义, 培养学生高度的社会责任感。比如, 讲到垃圾分类 时, 指出其实质是对废弃物进行分流处理, 提高其资源与经济价值, 物尽其用, 避免垃圾被简易处 理或填埋所造成的土壤、水体、空气等自然资源的严重恶化。在这些废弃物中, 有机物占有相当比 例, 目前的做法是依据其结构特点与性质进行处理, 比如蔬菜、果皮等可以通过发酵生产有机肥料, 废旧塑料类有机物可以回炼柴油等等, 由此引导学生积极思考: 在这场人与垃圾的战役中, 一个化 学人该如何正确运用所学有机化学知识去变废为宝、造福人类? 帮助学生明确化学人在知识运用中 的责任与担当, 正确的价值引领无疑为后续思政教学的开展打下良好的基础 ${ }^{[10]}$ 。

典型案例2: 霍夫曼的故事

作为一个古老的姓氏, 有机化学史上有多个著名的 “霍夫曼”。其中至少有三位与有机化学内 容相关, 一位与高等有机化学教学内容相关 ${ }^{[11]}$ 。经综合考虑, 在高等有机化学课程的 “周环反应” 一章、学习 “伍德沃德-霍夫曼规则” 时插入这一案例, 从Roald Hoffmann的故事自然地引申到有机 化学史上的其他几位霍夫曼。这种教学设计不仅可以帮助学生回顾总结有机化学相关知识, 而且还 可以帮助他们纠正错误认识、明晰每一位霍夫曼的科学贡献, 提高其自身专业文化底蕴和素养。在 教学过程中, 教师从案例出发, 因势利导, 进一步将思政教育提升到更高的哲学层次: August Wilhelm von Hoffmann的成功就是辩证唯物主义认识论在科学研究中的具体体现, 即 “观察-发现-分析-研究验证” ; 基于羟基的乙酰化反应, 拜耳公司的Felix Hoffmann分别合成了阿司匹林与海洛因, 底物不 同、结果则大相径庭, 科学研究也需要具体问题具体分析; Albert Hoffmann合成的麦角酸二乙基酰 胺(LSD) 可以是良药、也可以是毒品, 这正是唯物辩证法中 “质量互变” 规律的典型表现。综合协同 课程群中几位霍夫曼的科学故事, 从德育的角度还可以让学生明白一念天堂、一念地狱的道理, 从而帮助他们明辨是非, 树立正确的世界观、人生观与价值观, 将来更好地服务社会、造福人类。

典型案例3：回望《糖霜谱》

《糖霜谱》是宋代王灼撰写的我国第一部制糖专著, 放在糖化学基础课程 “寊糖”一章蔗糖部 分中作为育人案例。这一案例的知识点与有机化学实验相关联, 一方面可以让学生了解我国庶糖的 制作工艺与发展史, 提升专业文化底蕴、增强文化自信; 另一方面, 联系我国制糖术发展史 ${ }^{[12]}$, 让 学生认识到: 我国古代制糖技术的提升, 尤其是关键技术的进步, 更多的是碰巧、是受偶然性控制 的, 而不是主动作为的结果! 教学过程中紧扣这一案例, 以学生为主体、教师为主导, 进一步推广 至国人引以为傲的四大发明, 继而引用美国著名物理学家Henry Augustus Rowland在1883年所作的 “为纯科学呼吁” 的著名演讲, 引用科技日报原总编辑刘亚东先生2018年6月在中国科技会堂的演 
讲, 引导学生思考科学与技术之间的辩证关系, 明了技术背后的科学根源, 清楚地认识到: 我们只 有技术是远远不够的, 必须要用科学理论来指导、掌控我们的技术。在此基础上, 联系我国华为芯 片供应、北斗导航等核心技术问题及解决方案, 激发学生民族危机与社会使命感, 鼓励学生学好理 论知识, 用理论知识思考科学实践问题, 实现学以致用、知行合一的同时, 勇于担当, 科技报国。

\section{2 以学生为中心、教师为主导, 不断改进教学教法, 确保教育教学效果}

课堂教学是开展思政教育的主渠道。在教学过程中, 教师一定要转换角色, “以学生为中心、 教师为主导” , 教学可以通过微视频、学生阅读、好书推荐、课堂讨论、读书报告等形式, 灵活多 样, 易于被学生接受。目前我们已录制完成有机化学和糖化学基础课程思政的微课视频, 高等有机 化学课程也在积极准备中。新冠疫情下, 开启了 2020 年的春季学期, 笔者以此为契机, 结合我国各 行各业的典型抗疫事迹, 以书信形式殷切寄语, 鼓励学生感恩并珍惜当下, 好好学习, 明确自己当 前的责任与未来的担当。

在教学过程中, 我们还不定期通过课程小论文、问卷调查以检查思政育人效果。比如, 当讲到 格氏试剂与格氏反应时, 笔者分组布置学生查阅格林尼亚的相关资料。当多数同学在微信群里分享 诸如 “从浪子到科学家” “被骂醒的格林尼亚” 等阅读心得时, 一篇 “ “被励志” 的格林尼亚” 激 起了同学们极大的兴趣, 全文 8 页, 埌谐幽默、文采飞扬, 对 “浪子回头” 的故事进行了大胆质疑, 并附13页资料进行严谨考证, 最后还原了格林尼亚的真实形象。该文作者认为 “对于文献或百度百 科, 我们也不能不假思索、全盘接受。如果仍然盲目传播这种 “远古鸡汤” , 那么这将不仅是传播 它们的人们缺乏批判性思维的证明, 也是对真实历史的歪曲、对科学巨匠的不敬。”这一案例通过 文献的查阅、思考、撰写与分享, 在所有学生的心中留下了一个很深的印记, 无形中培养了他们的 批判性思维能力、科学探究精神与科学人文素养, 收到意想不到的思政育人效果。

在有机化学协同课程群的思政教学中, 一方面, 授课教师需重视并提炼出各课程的育人功能, 对课程的育人目标进行系统设计和定位。另一方面, 还要进一步在相关课程群间构建矩阵型育人模 式, 形成专业课程与思政课程、专业课程与专业课程间的协同效应。只有这样, 才能真正将专业课 打造成承载 “立德树人” 使命的金课, 造就适应并引领国家战略发展需要的研究性、复合型与应用 型化学人才。

\section{参 考 文 献}
[1] 张树永. 大学化学, 2019, 34 (11), 4.
[2] 王朝霞, 罗千福, 伍新燕, 俞善辉. 化工高等教育, 2018, No. 4, 47.
[3] 王志鹏, 程农壹, 马新雨, 田杰. 化学教育(中英文), 2019, 40 (10), 12.
[4] 王朝霞, 赵梅欣, 许胜, 罗千福. 大学化学, 2017, 32 (7), 54.
[5] 王朝霞, 俞晔, 罗千福. 化工高等教育, 2017, 34 (4), 105.
[6] 王朝霞, 伍新燕, 窦清玉, 罗千福. 大学化学, 2018, 33 (4), 21.
[7] 高佩茹, 钟世安,王艳, 徐海. 化学教育(中英文), 2018, 39 (22), 11.
[8] 赖绍聪. 中国大学教学, 2017, No. 12, 37.
[9] 陈波. 中国大学教学, 2017, No. 3, 22.
[10] 王朝霞, 罗千福, 徐首红. 大学化学, 2019, 34 (11), 45.
[11] 金浙东, 鲍政捷, 黄泽君, 王朝霞. 当代化工研究, 2019, No. 16, 83.
[12] 季羡林. 蔗糖史. 北京: 中国海关出版社, 2009. 